\title{
Influência da Corrente e Granulometria do Material de Adição nos Revestimentos Processados por PTA
}

\author{
(Evaluation of Deposition Current and Powders Grain Size During PTA Welding)
}

\author{
Danielle Bond', Sueli Fischer Becker', Ana Sofia C.M. D'Oliveira ${ }^{3}$ \\ ${ }^{1}$ Sociedade Educacional de Santa Catarina, Instituto Superior Tupy, Joinville, SC, Brasil, danielle.bond@sociesc.org.br \\ ${ }^{2}$ Universidade Federal de Santa Catarina, Centro de Engenharia da Mobilidade-CEM, Joinville, SC, Brasil, \\ sueli@joinville.ufsc.br \\ ${ }^{2}$ Universidade Federal do Paraná-Centro Politécnico, Departamento de Eng. Mecânica, Curitiba, PR, Brasil, sofmat@ufpr.br
}

\begin{abstract}
Resumo
Revestimentos soldados são aplicados com o intuito de prolongar a vida útil de componentes que operam em meios agressivos. Entre os processos de soldagem a deposição por plasma por arco transferido (PTA) tem sido reconhecida pelo processamento de depósitos homogêneos e densos, utilizando material de adição na forma de pó. A união de dois materiais com composições químicas diferentes, como no caso da aplicação de revestimentos, é sempre desafiadora. Esta união dependerá principalmente da otimização dos parâmetros de deposição utilizados, pois estes influenciam diretamente na microestrutura do revestimento e conseqüentemente no seu desempenho. O trabalho propõe identificar a relevância da granulometria do material de adição, intensidade e tipo de corrente, sobre a dureza de depósitos de uma liga de cobalto (Stellite 6) através do planejamento fatorial de experimentos. Resultados mostram que a granulometria do material de adição tem de ser considerada como variável de processamento em conjunto com parâmetros de processamento como a intensidade e modo de corrente.
\end{abstract}

Palavras-chave: Revestimento, Parâmetros de Deposição, Plasma por Arco Transferido (PTA), Soldagem, Pó.

Abstract: Welded coatings can be use to enhance the service life of components that operate under severe conditions. Plasma Transferred arc (PTA) is a hardfacing process, recognized for its homogeneous high quality deposits produced, and uses atomized feedstock. The bond of materials with different chemical compositions is always a challenge. This bond will depend on the optimization of the processing parameters, which influences the microstructure of the coatings and consequently its performance. This work analyzed the role of feedstock powder grain size, deposition current and mode on the hardness of a Co-based alloy (Stellite 6) coating using a experiment design tool. The results showed that the powder grain size of the feedstock has to be considered as a processing parameter together with the deposition current and mode as it influenced coating hardness.

Key-words: Coating, Processing Parameters, Plasma Transferred Arc (PTA), Welding, Powder.

\section{Introdução}

A campanha operacional de equipamentos que operam em ambientes agressivos pode ser ampliada se estes forem protegidos por revestimentos. Para isto existem várias técnicas de proteção superficial de componentes tais como: pintura, galvanização, metalização por aspersão térmica, cladização (chapas revestidas), eletrodeposição $(\mathrm{Cu}, \mathrm{Ni})$, por difusão (cementação e deposição em fase gasosa), redução química (niquelação), soldagem (hardfacing) [1,2].

O termo hardfacing refere-se à deposição de um revestimento soldado de composição química distinta daquela do metal de base (componente) com o objetivo de alcançar na superfície propriedades específicas e que o substrato não possui. Existe

(Recebido em 07/10/2010; Texto final em 25/03/2011).

Artigo originalmente publicado no COBEF 2009 uma grande variedade de materiais que podem ser aplicados como revestimentos, entre os mais importantes destacam-se as superligas a base de níquel e a base de cobalto. Os substratos mais comumente utilizados são os aços de baixo carbono ou médio carbono e os aços inoxidáveis, [2, 3]. As superligas a base de níquel são conhecidas pela excelente resistência à corrosão em elevadas temperaturas. Já aquelas a base de cobalto destacam-se pela elevada resistência ao desgaste, sendo a mais e empregada a superliga denominada Stellite 6. Este material possui excelente resistência às várias formas de degradação química e mecânica sob temperaturas, mantém a dureza até $800^{\circ} \mathrm{C}$, e tem baixa tendência ao aparecimento de trincas [4]. No entanto, as propriedades dos revestimentos de ligas de cobalto dependem do processo de deposição e para cada tipo de processo, dos parâmetros de processamento utilizados. Para a deposição são utilizados os processos de soldagem oxigás, a arco e laser, os quais são aplicados, preferencialmente, para obter espessuras maiores quando comparados aos processos de aspersão térmica, nos quais ocorre um ancoramento mecânico entre material de base e o revestimento [2]. Segundo Wu et al [3] 
e Tarng et al [5], os processos de soldagem mais utilizados são: soldagem oxiacetilênica, TIG (tungsten inert gas), MIG/MAG (metal inert gas/ metal active gas), arco submerso e plasma por arco transferido (PTA). O PTA também pode ser inserido nos processos de aspersão térmica em função do spray térmico decorrente das características do material de adição.

A deposição por Plasma com arco transferido (PTA) é um processo que evoluiu da técnica de soldagem TIG (tungsten inert gas), e envolve um arco elétrico estabelecido entre um eletrodo de tungstênio não consumível e a peça, Figura 1 [2]. O PTA que utiliza material de adição na forma de pó (mistura de pós ou ligas atomizadas), tem sido referenciado pela deposição de revestimentos soldados de excelente qualidade. Quando comparado com outros processos de soldagem, sua diluição é menor (5 a 20\%), bem como a distorção do corpo de prova provocada pelo calor [2].

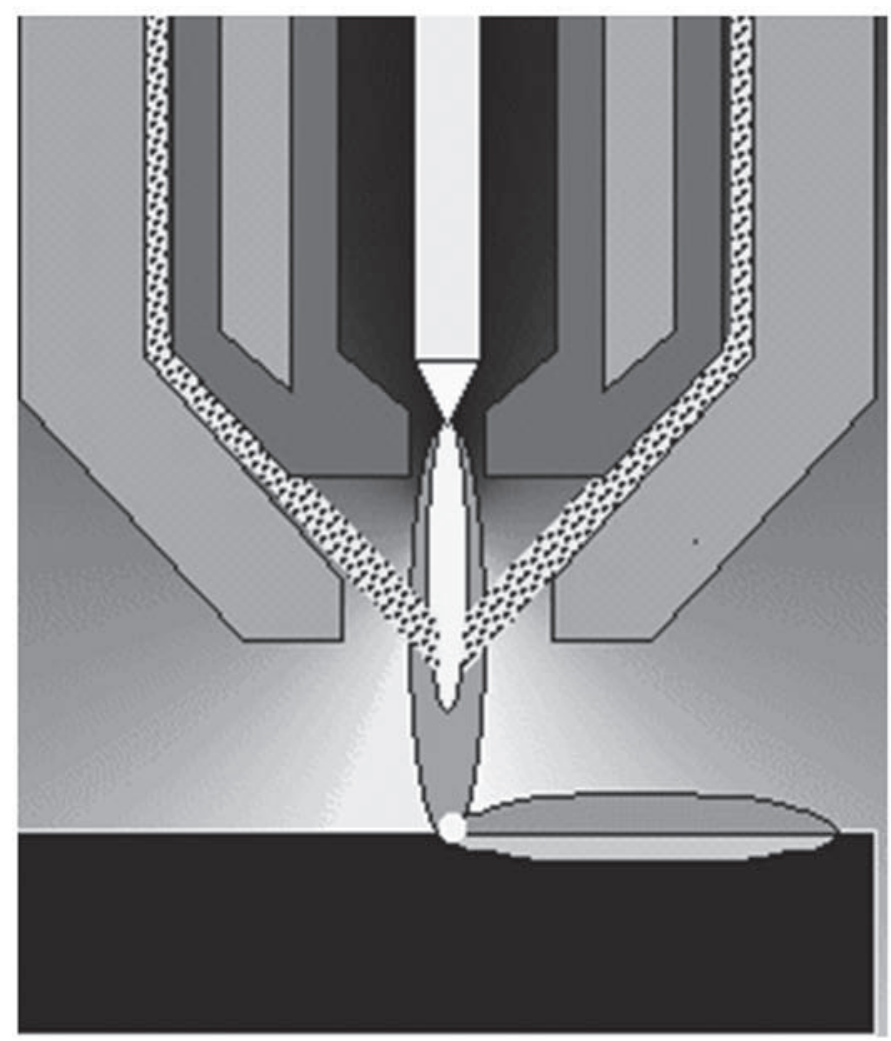

Figura 1. Desenho esquemático do arco constrito com alimentação com material atomizado - PTA [6].

Destaca-se ainda que a literatura faz referência ao processo PTA, por produzir depósitos com estruturas mais refinadas quando comparadas aquelas obtidas por outros processos de soldagem de revestimentos, que utilizam materiais de adição na forma de arames, sugerindo que a condição atomizada da liga a ser depositada pode interferir nas características dos depósitos [7-9]. Efetivamente poucos trabalhos são encontrados a respeito e, na maioria, as comparações são realizadas entre técnicas de deposição com características bem diferentes entre si [10-16].

A análise do comportamento térmico da partícula (material de adição) ao cruzar o arco de plasma pode prever a que temperatura e/ou estado físico que a liga atomizada chega na poça de fusão. Xibao e Hua (1998) estudaram o comportamento térmico de ligas atomizadas a base de Fe, com diferentes tamanhos de partícula, depositadas por PTA. Nas condições limites estudadas têm-se que as partículas da maior tamanho atingem a poça de fusão com temperaturas menores e as processadas com maior intensidade de corrente chegam na poça de fusão com temperaturas mais elevadas [17]. Sendo assim a distribuição de granulometria das partículas da liga atomizada deve influenciar as características do revestimento. O efeito da temperatura que as partículas atomizadas atingem no arco também pode ser identificado no estudo em que Díaz (2005) comparou a qualidade dos depósitos utilizando dois bocais de alimentação de pó que direcionam o pó para a parte superior do arco ou para junto à poça de fusão [8]. De acordo com os resultados apresentados pode-se interpretar que dependendo da DTP, as partículas ficam sujeitas a temperaturas e tempos de permanência diferentes no arco de plasma, atingindo a poça de fusão com temperaturas diferentes (de maneira análoga quando a distância tocha-peça é alterada). Consequentemente, a solidificação da poça de fusão poderá ser modificada refletindo em mudanças tanto microestruturais quanto nos níveis de dureza dos revestimentos.

Aintensidade deaquecimento das partículas daligaatomizada a ser depositada depende dos parâmetros de processamento e da distribuição granulométrica. A variação desses parâmetros altera a temperatura que as partículas atingem no arco e que chegam na poça de fusão podendo influenciar a solidificação e consequentemente as propriedades dos revestimentos. É neste contexto que o presente trabalho se enquadra ao propor uma análise sistemática do efeito da intensidade e modo de corrente de deposição e do tamanho médio das partículas da liga atomizada sobre a dureza de revestimentos de Stellite 6 processados por PTA, recorrendo a um planejamento fatorial de experimentos.

\section{Materiais e Métodos}

Revestimentos da liga a base de Co - Stellite 6, com partículas de granulometria entre $45-180 \mu \mathrm{m}$, foram processados por Plasma com Arco Transferido em chapas 100x100x12,7mm de aço SAE 1020.

Um planejamento fatorial de experimentos permite que as combinações entre os níveis dos fatores escolhidos sejam investigados, o que é de grande interesse sempre que vários fatores competem em um experimento. Neste estudo, conduziuse um planejamento experimental $2^{4}$, com quatro fatores e dois níveis, conforme relacionados na Tabela 1 . 
Tabela 1. Fatores e níveis do planejamento fatorial realizado.

\begin{tabular}{c|c|c}
\hline Fator & \multicolumn{2}{|c}{ Níveis } \\
\hline Distância Tocha-Peça & $10 \mathrm{~mm}$ & $20 \mathrm{~mm}$ \\
\hline Granulometria & Comercial (0) & Comercial com adição de 35 \%massa de finos (35) \\
\hline Intensidade de corrente & $100 \mathrm{~A}$ & $130 \mathrm{~A}$ \\
\hline Tipo de corrente & Constante (C) & Pulsada (P) \\
\hline
\end{tabular}

Tabela 2. Parâmetros utilizados com corrente pulada.

\begin{tabular}{c|c|c|c|c}
\hline \multirow{2}{*}{$\begin{array}{c}\text { Intensidade da } \\
\text { Corrente Média }\end{array}$} & $\begin{array}{c}\text { Tempo de pico } \\
(\mathrm{ms})\end{array}$ & $\begin{array}{c}\text { Tempo de base } \\
(\mathrm{ms})\end{array}$ & $\begin{array}{c}\text { Corrente de base } \\
(\mathrm{A})\end{array}$ & $\begin{array}{c}\text { Corrente de pico } \\
(\mathrm{A})\end{array}$ \\
\cline { 2 - 5 } & 5 & 8 & 75 & 140 \\
\hline $100 \mathrm{~A}$ & 5 & 8 & 75 & 218 \\
\hline $130 \mathrm{~A}$ & 5 & 8 & 75 \\
\hline
\end{tabular}

Os fatores considerados no planejamento fatorial foram:

- Distância tocha-peça (DTP): O nível de $10 \mathrm{~mm}$ é decorrente da distância tocha-peça recomendada para obtenção de cordões íntegros nas condições de processamento consideradas neste trabalho. Mesmo correndo o risco de ocorrer uma falta de fusão dos cordões, foi selecionado o nível de $20 \mathrm{~mm}$, objetivando obter uma diferença significativa no aquecimento das partículas no plasma;

- Granulometria: foram considerados dois níveis a granulometria comercial $(45 \mu$ a $180 \mu)$ com e sem adição de $35 \%$ massa de finos $(45 \mu)$ da mesma composição química da liga atomizada. Intensidade de corrente: foram ensaiados os níveis de 100 A e 130 A;

- Tipo de corrente: os níveis considerados foram a corrente contínua constante e a corrente contínua pulsada, esta com a frequência de pulso de $77 \mathrm{~Hz}$ e a relação tp/tb de 0,6 , conforme relatado na Tabela 2 .

À medida que cresce o número de fatores em um experimento fatorial, aumenta também o número de efeitos que podem ser estimados. Por exemplo, quando o número de fatores é grande, como neste caso 4 , uma prática comum é rodar apenas uma replicação de planejamento $2^{\mathrm{k}} \mathrm{e}$ então combinar as interações de ordem maior como uma estimativa do erro [18]. As rodadas do experimento foram realizadas aleatoriamente, sendo as combinações entre fatores e níveis apresentados na Tabela 3 .

Como variável de resposta ao experimento foi medida a microdureza Vickers (HV 0,5) dos revestimentos processados, e considerando que as diferenças que se procuram pequenas utilizou-se a carga de $0.5 \mathrm{kgf}$ para minimizar oscilações decorrentes de variações na proporção das fases. Cada valor de microdureza corresponde a média de 11 medidas realizadas na seção transversal de cada revestimento (Figura 2). Foram estimados os intervalos de confiança bilaterais para cada média obtida, considerando um nível de confiança de $95 \%$, de acordo com a Tabela 3.

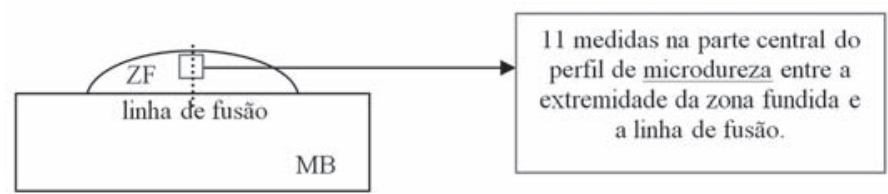

Figura 2. Localização das medições de microdureza realizadas na seção transversal do cordão de solda.

As medidas de microdureza foram feitas a uma distância de $0,125 \mathrm{~mm}$ da superfície externa do depósito e as demais identações realizadas com o espaçamento de $0.20 \mathrm{~mm}$. As fases presentes no revestimento foram analisadas através de difração de raios-X na superfície externa dos cordões após desbaste de $1,5 \mathrm{~mm}$ para se obter uma superfície plana e maximizar potencial influência do substrato.

\section{Resultados e Discussão}

A Tabela 3 apresenta as medidas obtidas para cada experimento, como também os intervalos de confiança bilaterais para cada média obtida. As quatro primeiras colunas relacionam os níveis de cada fator avaliados durante cada ensaio. A penúltima coluna relata a variável de resposta estudada (a microdureza média), e na última coluna é dado o intervalo com $95 \%$ de confiança para a microdureza média. 
Tabela 3. Dados obtidos nos experimentos.

\begin{tabular}{|c|c|c|c|c|c|}
\hline $\begin{array}{l}\text { Intensidade } \\
\text { Corrente (I) }\end{array}$ & $\begin{array}{l}\text { Tipo Corrente } \\
\text { (constante ou } \\
\text { pulsada) }\end{array}$ & $\begin{array}{c}\text { Granulometria } \\
(\% \text { finos } \\
\text { adicionados })\end{array}$ & $\begin{array}{c}\text { Distância } \\
\text { Tocha-Peça (mm) }\end{array}$ & $\begin{array}{c}\text { Média } \\
\text { Microdureza } \\
(\mathrm{HV} 0,5)\end{array}$ & $\begin{array}{c}\text { Intervalo de Confiança } \\
\text { para média } \\
\text { (Nível 95\%) }\end{array}$ \\
\hline 100 & $\mathrm{C}$ & 0 & 10 & 440 & $(436,444)$ \\
\hline 100 & $\mathrm{P}$ & 0 & 10 & 427 & $(421,433)$ \\
\hline 100 & $\mathrm{C}$ & 35 & 10 & 464 & $(460,467)$ \\
\hline 100 & $\mathrm{P}$ & 35 & 10 & 467 & $(458,475)$ \\
\hline 100 & $\mathrm{C}$ & 0 & 20 & 472 & $(465,480)$ \\
\hline 100 & $\mathrm{P}$ & 0 & 20 & 471 & $(458,484)$ \\
\hline 100 & $\mathrm{C}$ & 35 & 20 & 450 & $(432,468)$ \\
\hline 100 & $\mathrm{P}$ & 35 & 20 & 477 & $(464,490)$ \\
\hline 130 & $\mathrm{C}$ & 0 & 10 & 414 & $(403,425)$ \\
\hline 130 & $\mathrm{P}$ & 0 & 10 & 420 & $(408,433)$ \\
\hline 130 & $\mathrm{C}$ & 35 & 10 & 467 & $(459,475)$ \\
\hline 130 & $\mathrm{P}$ & 35 & 10 & 414 & $(403,425)$ \\
\hline 130 & $\mathrm{C}$ & 0 & 20 & 459 & $(445,471)$ \\
\hline 130 & $\mathrm{P}$ & 0 & 20 & 477 & $(467,487)$ \\
\hline 130 & $\mathrm{C}$ & 35 & 20 & 471 & $(459,482)$ \\
\hline 130 & $\mathrm{P}$ & 35 & 20 & 470 & $(449,490)$ \\
\hline
\end{tabular}

As variações microestruturais ocorridas durante a solidificação de revestimentos soldados, tanto as decorrentes da alteração da composição química (mudança de fase e quantidade de região interdendritica) como as da taxa de solidificação (refino da microestrutura), são refletidas em variações na microdureza do revestimento em maior ou menor intensidade dependendo da magnitude das alterações. Apesar da extrapolação destes valores para prever a resistência ao desgaste ser limitada, a dureza tem sido amplamente utilizado na avaliação de revestimentos por PTA [14, 19-23].

Para as condições de processamento testadas, as microestruturas do cordão consistem numa região dendrítica de solução sólida rica em cobalto $(\alpha)$, e na região interdendrítica pode se encontrar o eutético ( $\alpha$ e carbonetos), Figura 3. A análise por difração de raios $\mathrm{X}$ mostra que a variação de dureza dos revestimentos obtidos não é proveniente da mudança de fase decorrente do processamento. Este comportamento foi observado na comparação entre os difratogramas do material de adição e revestimento processado com corrente contínua constante de 130A, Figura 4a, assim como com a mudança do tipo de corrente (para contínua pulsada), Figura 4b. Os resultados mostram que a principal fase identificada na liga atomizada é a solução sólida rica em Co e que esta se mantém no revestimento para o mesmo ângulo $2 \theta$. A análise dos revestimentos processados com corrente contínua constante e contínua pulsada confirmam que não ocorrem mudanças de fase. Assim, as alterações de dureza medidas estão relacionadas à proporção de fases e refino da microestrutura.
Os dados obtidos no experimento $2^{4}$ foram compilados em software especializado, e os efeitos estão representados no gráfico de probabilidade normal, Figura 5, sendo que no eixo $\mathrm{X}$ estão representados as estimativas dos efeitos e no eixo $\mathrm{Y}$ estão os escores normais padrão $z$. Conforme Montgomery (2004), se nenhum dos efeitos é significante, então as estimativas se comportarão como uma amostra aleatória extraída de uma distribuição normal com média zero, e os efeitos estarão localizados aproximadamente ao longo de uma linha reta [18]. Considerando um nível de confiança de $95 \%$, é possível verificar por meio deste gráfico que o efeito principal da distância tochapeça (DTP) caracterizou-se como significativo durante o processamento do revestimento, porque ele se encontra afastado da linha passando através dos outros efeitos.

A natureza colunar e a força do arco constrito fazem da soldagem a plasma um processo pouco sensível a variação do parâmetro DTP. Este fato acaba se tornando uma vantagem, já que é possível a utilização de comprimentos de arco relativamente longos sem que haja uma redução significativa na concentração de energia até um limite que permita manter estas características [24]. Oliveira (2001) num estudo da soldagem a plasma com alimentação automática de arame para aplicação em revestimentos metálicos observou a manutenção da forma cilíndrica do arco com o aumento da DPT para os valores estudados [25]. É ainda reportado que as alterações nos cordões processados com arame alimentado em regiões distintas do arco estão associadas a temperatura que o material atinge no arco e chega na poça de fusão. Apesar de não ser comentado 


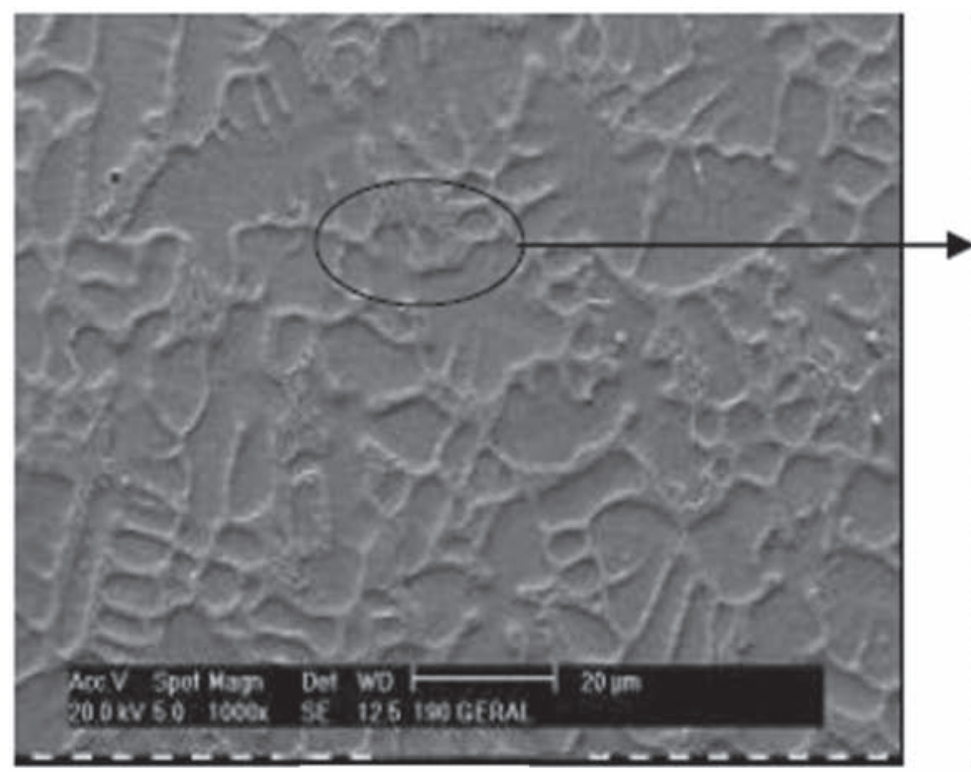

Figura 3a

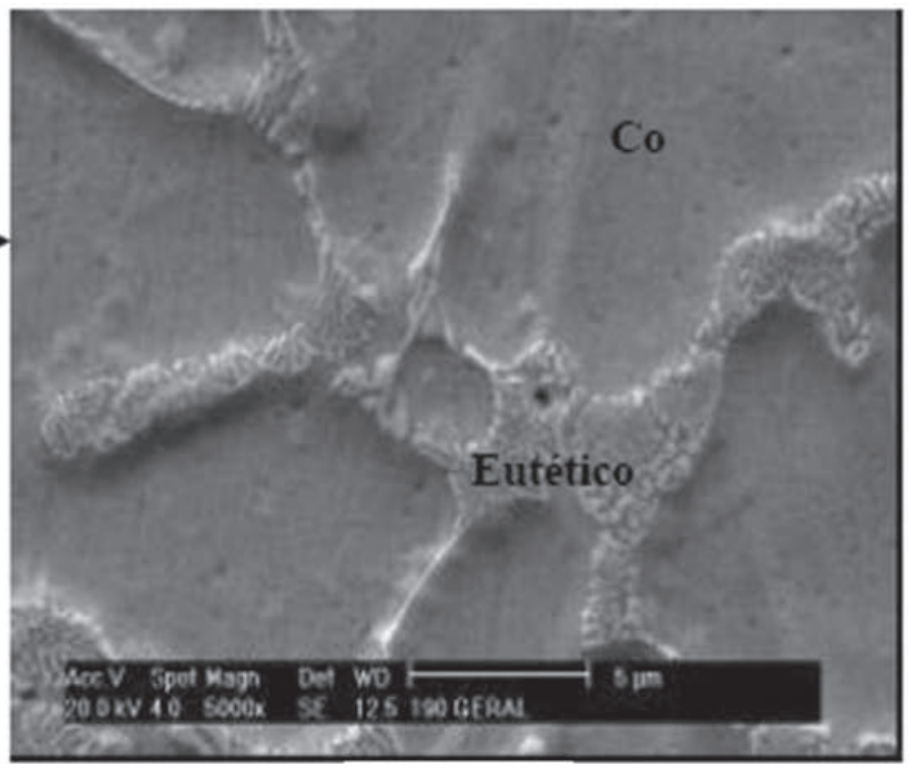

Figura $3 b$

Figura 3. Microestrutura dos revestimentos.

Fig. 3a: aspecto geral da estrutura na região central dos revestimentos.

Fig. 3b: detalhe da estrutura dos revestimentos, onde se observa região dendrítica rica em Co e o eutético interdendrítico.

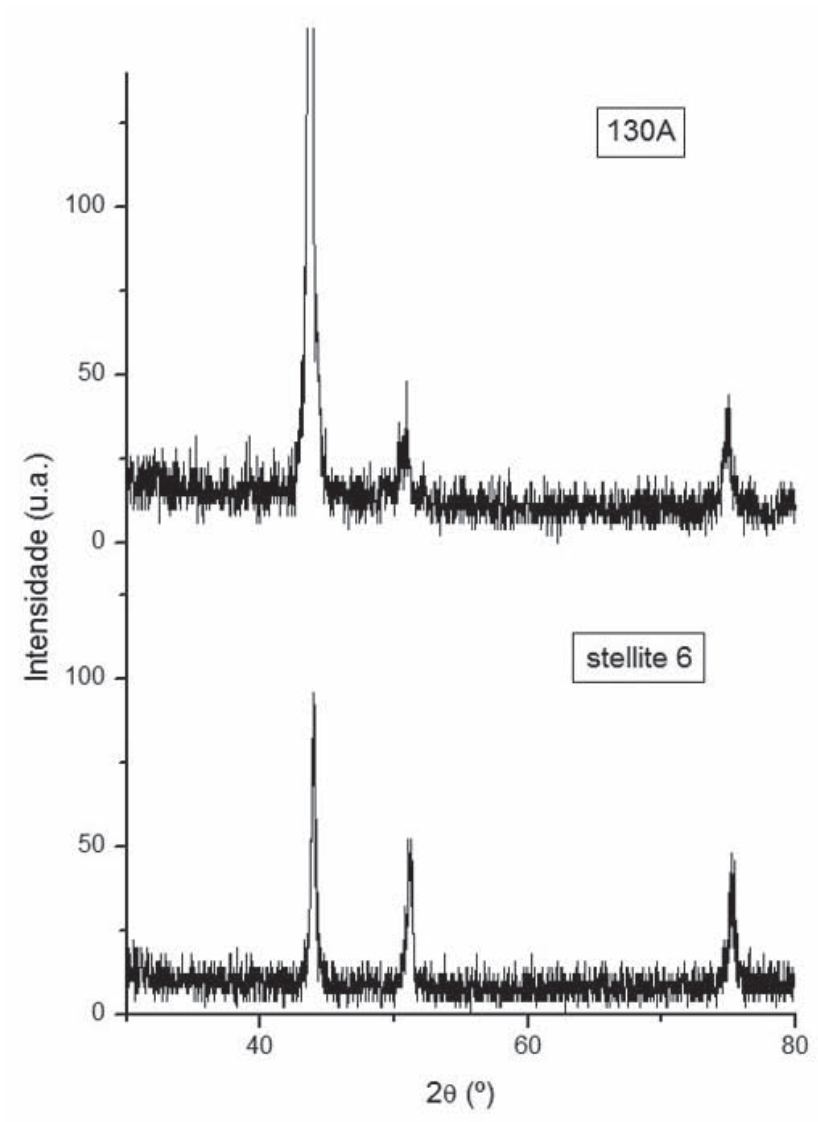

Figura 4a

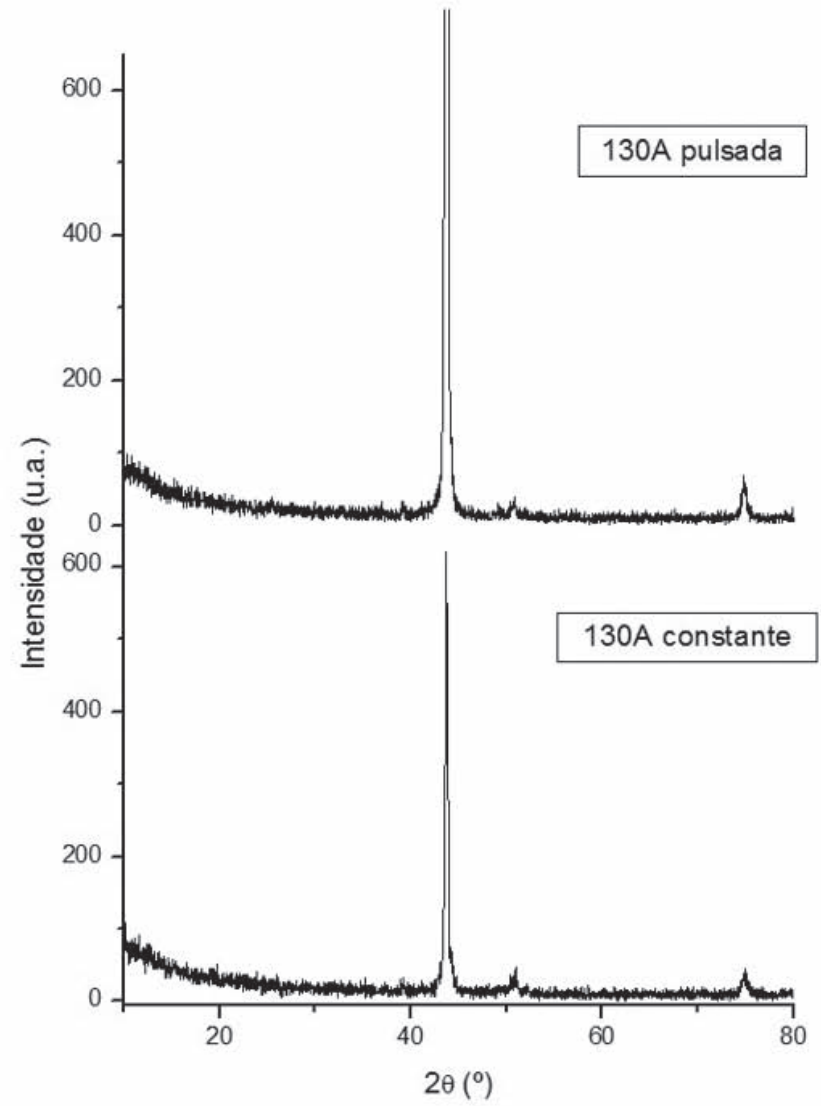

Figura $4 b$

Figura 4. Comparação entre os difratogramas dos revestimentos processados em condições diferenciadas.

Fig. 4a: material de adição (pó comercial de Stellite6) e revestimento processado com corrente contínua constante (I=130A);

Fig. 4b: revestimentos processados com corrente contínua constante e pulsada. 


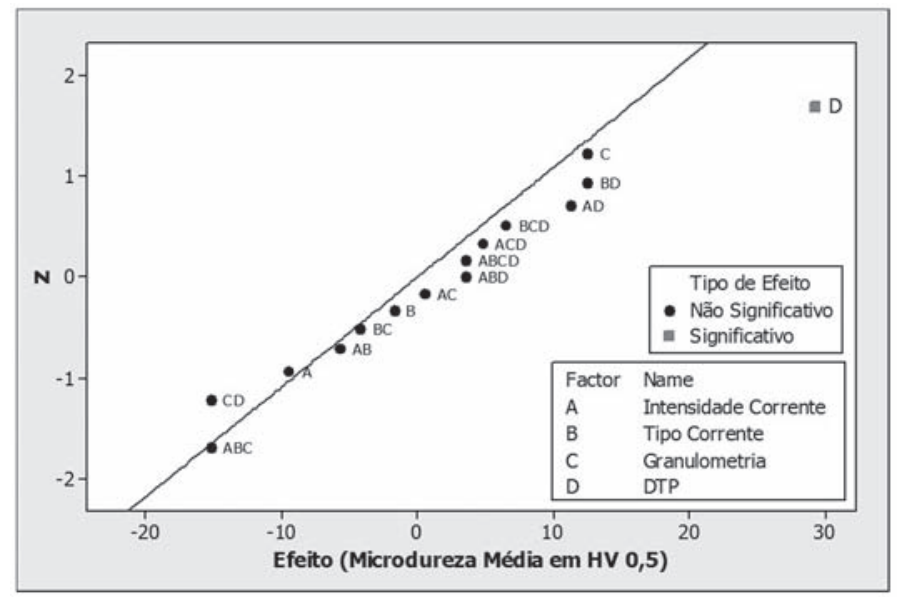

Figura 5. Gráfico da probabilidade normal dos efeitos, a partir do experimento fatorial $2^{4}$ de processamento do revestimento.

pelo autor, este comportamento pode influenciar nas etapas de nucleação e crescimento da solidificação dos revestimentos. Ao se depositar ligas atomizadas este comportamento é amplificado pelo pequeno volume de cada partícula a ser aquecida, que é bem menor que o volume de arame. Assim, o aumento da DTP determina a temperatura que cada uma das partículas da liga atomizada pode atingir no arco voltaico. A entrada do fluxo de material atomizado é feita através do bico constritor que, além de produzir a constrição do arco, permite a entrada do material de adição de forma convergente na coluna do plasma. Se o material atomizado é alimentado numa distância tocha-peça (DTP) maior (20mm), Figura 6, as partículas ficam sujeitas a temperaturas e tempos de permanência diferentes quando comparadas com as de menor distância tocha peça $(10 \mathrm{~mm})$, o que vai influenciar a temperatura com que as partículas chegam na poça de fusão e a solidificação do cordão, em consequência a microdureza.

\section{Arco Constrito - PTA}

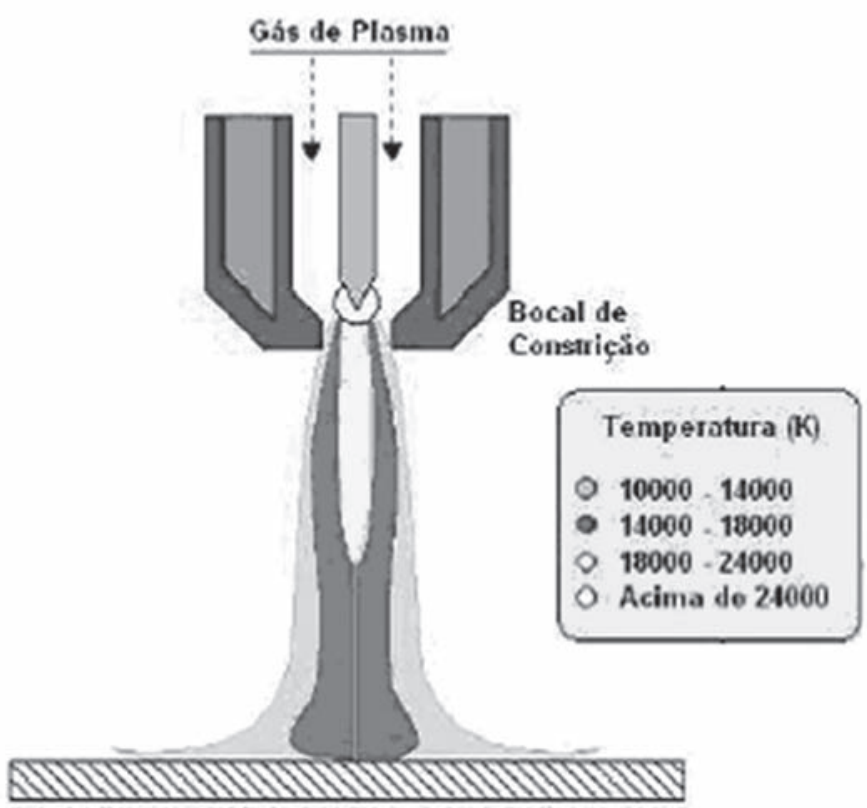

Figura 6. Correlação entre distribuição de temperaturas no plasma e posição de alimentação do material atomizado. Adaptado de Marconi e Marconi (2002) [26].

Análise metalográfica dos cordões processados com diferentes DTP revelou que o aumento da distância tocha-peça (de 10 para $20 \mathrm{~mm}$ ) resultou em cordões com falta de fusão, Figura 7. Portanto, a DTP de $20 \mathrm{~mm}$ foi excessiva e reduziu tanto a penetração que levou a que em algumas regiões ocorresse falta de fusão.

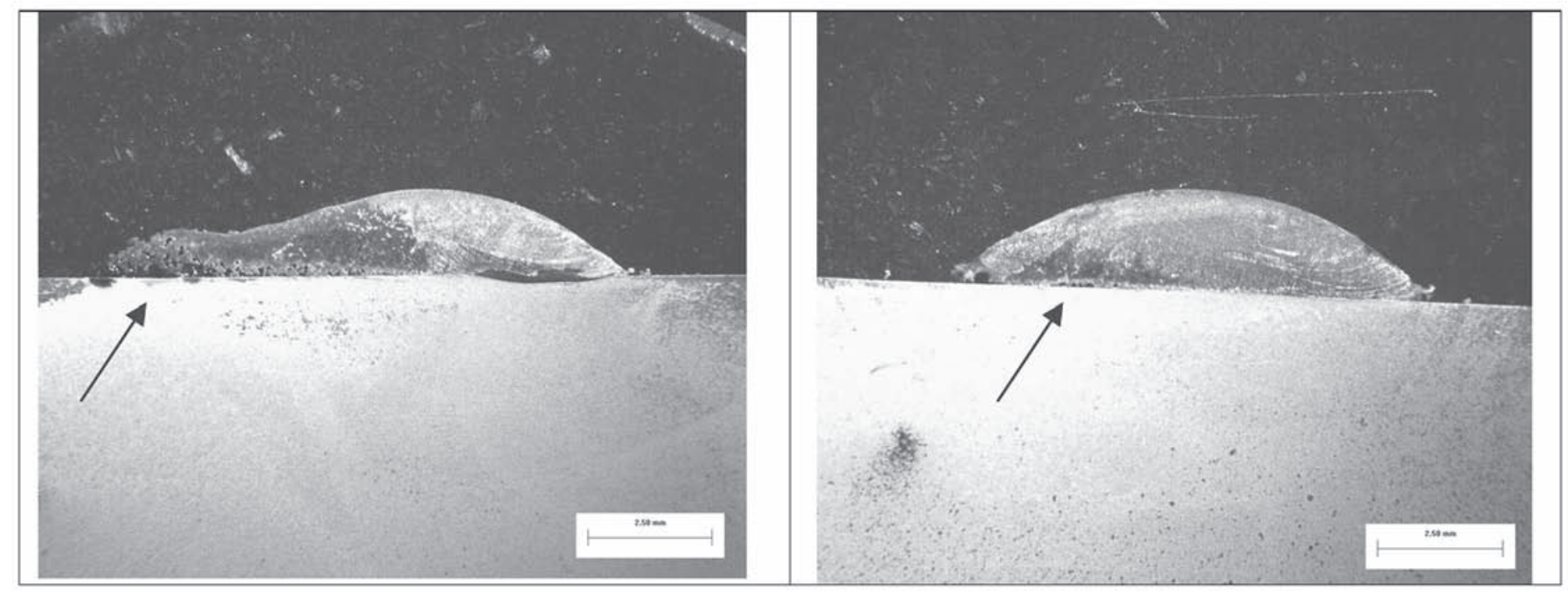

Figura 7. Falta de fusão com o aumento da distância tocha-peça (20mm). 
Regiões com falta de fusão resultam em revestimentos menos afetados pelo substrato, em particular, o aumento do teor de ferro (do substrato) contribui para uma redução de dureza em ligas de cobalto [27]. Esta condição se sobrepõe ao efeito que a granulometria da liga atomizada possa ter na intensidade de aquecimento que as suas partículas da liga atomizada são expostas na deposição e em consequência da granulometria da estrutura de solidificação do revestimento. Este comportamento explica os maiores valores de microdureza dos revestimentos processados com a maior DTP, tanto para a condição com corrente contínua constante quanto para a contínua pulsada, pois não houve mistura do revestimento com o metal de base. Por isso este fator se destacou como o de maior significância no experimento fatorial (os níveis de dureza foram muito superiores aos demais).

Refinando a análise, os dados experimentais foram reavaliados considerando apenas os cordões processados com DTP de $10 \mathrm{~mm}$, reduzindo para um experimento fatorial $2^{3}$.É possível verificar através do gráfico da probabilidade normal que todos os pontos estão próximos da linha reta (Figura 8), exigindo assim uma avaliação dos impactos dos fatores testados.

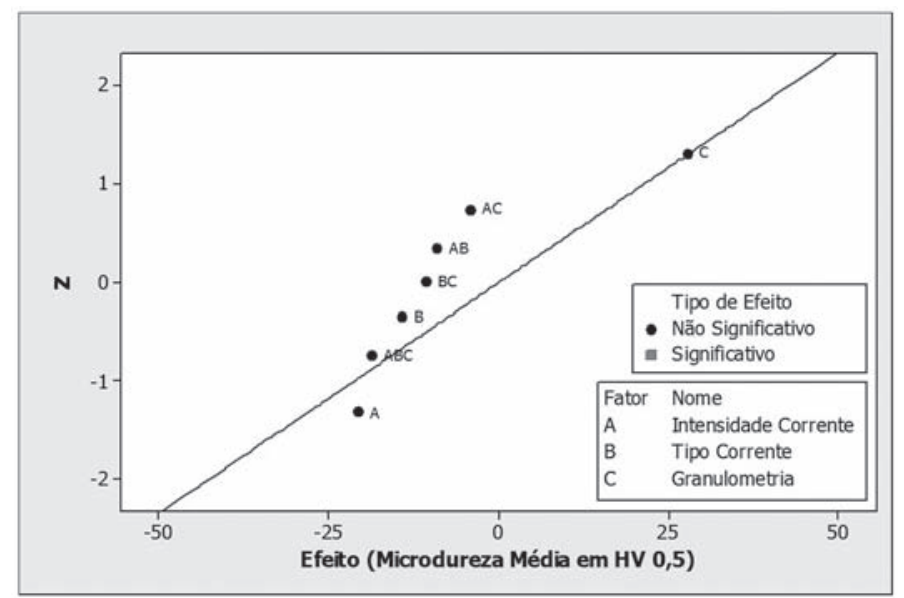

Figura 8. Gráfico da probabilidade normal dos efeitos, a partir do experimento fatorial $2^{3}$ de processamento do revestimento

Uma análise detalhada destes resultados considerou as microdurezas representadas por seus intervalos de confiança, calculados para um nível de confiança de 95\%, Figura 9, permitindo avaliação par a par das variações ocorridas decorrentes das combinações dos níveis de fator em cada rodada.

É esperado que o aumento da corrente de 100 para $130 \mathrm{~A}$ provoque um aumento do aporte térmico o qual tem influência na solidificação da poça de fusão, uma vez que interfere diretamente no gradiente térmico $(\mathrm{G})$ do líquido junto à interface sólido/líquido. Com o aumento do aporte de calor ocorre uma diminuição do gradiente térmico $(\mathrm{G})$, e consequente redução da velocidade de resfriamento diminuindo o refinamento da microestrutura e dureza. Esta relação é um pouco alterada quando se depositam ligas atomizadas pois as partículas atomizadas absorvem muita energia reduzindo a energia que chega ao substrato. Entretanto não se altera a tendência para o

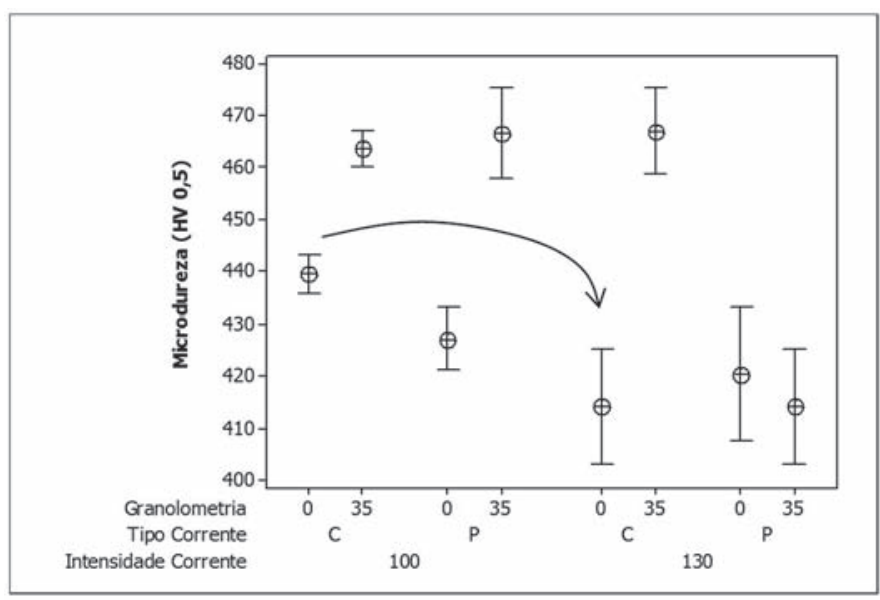

Figura 9. Intervalos de confiança de $95 \%$ para a microdureza média, para o experimento fatorial $2^{3}$ de processamento de revestimento.

aumento da diluição e redução de velocidade de resfriamento com o aumento da corrente de deposição, como confirmam os valores de microdureza medidos nos revestimentos processados com corrente continua constante após aumento da corrente de 100A para 130A. Na Figura 9 pode-se verificar que para a liga de Co atomizada com a granulometria comercial o aumento da intensidade de corrente contínua constante provocou diminuição na média dos valores de dureza (comportamento destacado pela seta). Vários fatores colaboram para esta redução nos níveis de dureza, além de diminuir a velocidade de resfriamento, o aumento da intensidade de corrente provoca um aumento da diluição que mesmo não alterando as fases presentes, diminuiu a dureza do revestimento, pois aumentou a quantidade de elementos do substrato incorporada à poça de fusão. Entretanto, tendência diferente foi observada nos revestimentos processados com o tamanho de partícula médio menor, pela adição de $35 \%$ em massa de partículas finas com diâmetro de $45 \mu \mathrm{m}$. Este comportamento pode ser explicado, considerando a temperatura que cada partícula atinge no arco e a temperatura com que cada uma chega na poça de fusão, seguindo tendência proposta por Wilbao e Hua [17] em seu estudo com partículas de Fe-CrC.

Para explicar as características de revestimentos processados com ligas atomizadas com diferentes granulometrias propõemse a seguinte hipótese para descrever o comportamento das partículas durante a deposição:

Partículas menores, em função da sua menor massa fundem mais facilmente podendo atingir temperaturas mais elevadas ao passar pelo arco de plasma. Assim, partículas maiores podem chegar na poça de fusão aquecidas ou parcialmente fundidas enquanto que partículas menores poderão chegar na poça de fusão sobreaquecidas ou se chegarem a vaporizar nem chegarão à poça de fusão. As partículas sobreaquecidas deverão ser incorporadas a poça de fusão e não terão papel significativo na estrutura de solidificação. Já as partículas que chegam na poça de fusão com temperaturas próximas a sua temperatura de solidificação ou com temperaturas até um pouco inferiores tendem a iniciar o processo de solidificação de imediato, gerando vários núcleos e contribuindo para o refino da estrutura e em consequência 
aumento da dureza do revestimento.

Corroboram para esta hipótese os cordões processados com os mesmos parâmetros de deposição variando apenas a granulometria média das partículas da liga atomizada, que exibem um aumento na dureza quando processamentos com material de granulometria média menor, isto é, com a adição de $35 \%$ em massa de finos. Sugerindo que uma maior densidade de núcleos se formou gerando uma estrutura mais refina e em decorrência revestimentos com maior dureza. A exceção a este comportamento são os cordões processados com corrente média de $130 \mathrm{~A}$ no modo contínuo pulsado que exibiram uma queda na dureza média, e que pode ser compreendida pela elevada corrente de pico utilizada nesta condição (218A) que gerou um aquecimento excessivo das partículas mais finas provocando o seu sobreaquecimento o que levou a sua incorporação total na poça de fusão impedindo a sua ação enquanto núcleos e ou até mesmo a sua eventual vaporização. Este mesmo argumento permite explicar a queda de dureza dos revestimentos processamentos com diferentes modos de corrente (contínua constante e contínua pulsada) utilizando o material de adição de menor granulometria média.

\section{Conclusões}

O estudo da influência da granulometria média de uma liga de Co atomizada (Stellite 6) e da intensidade e modo de corrente em revestimentos processados por Plasma com Arco Transferido (PTA) nas condições de estudo é possível concluir:

A granulometria média da liga a ser depositada influencia as características dos revestimentos, medida pela sua dureza e deve ser considerada em conjunto com a variação da intensidade e modo de corrente de deposição. A temperatura que as partículas da liga atomizada atingem no arco e com que chegam na poça de fusão depende destes parâmetros de processamento e irão determinar se a estrutura dos revestimentos será mais ou menos refinada, e em consequência suas propriedades.

\section{Agradecimentos}

Este trabalho conta com o apoio da Agência Nacional do Petróleo - ANP - e da Financiadora de Estudos e Projetos FINEP - por meio do Programa de Recursos Humanos da ANP para o Setor Petróleo e Gás - PRH-ANP/MCT, com recursos financeiros disponibilizados através do PRH-24. Os autores agradecem também o apoio do grupo de pesquisa de engenharia de superfícies-UFPR, LORXI - UFPR e IST-SOCIESC.

\section{Referências Bibliográficas}

[1] GENTIL, V. Corrosão. 4.ed. Rio de Janeiro: LTC-Livros Técnicos e Científicos Editora S.A., 2003.

[2] DAVIS, J.R. Hardfacing, weld cladding, and dissimilar metal joining. In: METALS HANDBOOK. Welding, Brazing and Soldering. 10.ed., v.6. Ohio: ASM International, 1993.

[3] WU, W., WU, L. The wear behaviour between hardfacing materials. Metallurgical and Materials Transactions A, v. 27A, 1996.

[4] DELORO STELLITE, apresenta as características de seus produtos, disponível em: http://www.stellite.co.uk/Products/ PTALaserPowder/tabid/66/Default.aspx. acesso em: 28 novembro 2007.

[5] TARNG, Y.S.; JUANG, S.C.; CHANG, C.H. The use of grey-based Taguchi methods to determine submerged arc welding process parameters in hardfacing. Journal of Materials Processing Technology, v.128, n. 1-3, p.1-6, 2002.

[6] PLASMA TEAM. Apresenta informações sobre a empresa. Disponível em: http://www.plasmateam.com/products. Acesso em 05 setembro 2007.

[7] SILVÉRIO, R.B., D OLIVEIRA, A.S.C.M. Revestimento de liga a base de cobalto por PTA com alimentação de pó e arame. In: Congresso Brasileiro de Engenharia de Fabricação, $2^{\circ}, 2003$, Uberlândia.

[8] DÍAZ, V.M.V. Inovação do equipamento e avaliação do processo plasma de arco transferido alimentado com pó (PTAP) para soldagem fora de posição. 2005. Tese (Doutorado em Engenharia Mecânica) - Programa de Pós-Graduação em Engenharia Mecânica, UFSC, Florianópolis.

[9] BOND, D. Avaliação de revestimentos soldados processados com materiais atomizados. 2008. Tese (Doutorado em Engenharia) - Programa de Pós-Graduação em Engenharia de Materiais e Processos-PIPE, UFPR, Curitiba.

[10] LUGSCHEIDER, E. ; OBERLANDER, B. C.A . Comparison of the Properties of Coatings Produced by Laser Cladding and Conventional Methods. Materials Science and Technology, v..8, n.8, p.657-665, 1992.

[11] LIMA, C.R.C.; CAMARGO, F.; MARQUES, P.V. Estudo comparativo das propriedades de revestimentos a base de cobalto (Stellite) aplicados por soldagem e por aspersão térmica, In: XXIV Encontro Nacional de Tecnologia da Soldagem, 1998, Fortaleza.,

[12] MOHANDAS, G. et al. A comparative evaluation of gas tungsten and shielded metal arc welds of a ferritic stainless steel. Journal of Materials Processing Technology, v. 94, n.2-3, p 133140, 1999.

[13] FOLTRAN, B. Comparação dos revestimentos de superligas à base de cobalto (Co-Cr-W-C) depositados por eletrodo revestido, plasma por arco transferido e laser. 2000. Dissertação (Mestrado em Engenharia de Materiais e Processos) - Programa de Pós-Graduação em Engenharia de Materiais e ProcessosPIPE, UFPR, Curitiba.

[14] D’OLIVEIRA, A. S. C. M., VILAR, R., FEDER, C.G. High temperature behaviour of plasma transferred arc and laser Cobased alloy coatings. Applied Surface Science, v.2001, n.1-4, p.154-160, 2002.

[15] KLIMPEL, A. ET al. The study of the technology of laser and plasma surfacing of engine valves face made of $\mathrm{X} 40 \mathrm{CrSiMo10-2}$ steel using cobalt-based powders. Journal of 
Materials Processing Technology, v.175, n.1-3, p.251-256, 2006. [16] BUCHANAN, V.E; MC CARTNEY, D.G.; SHIPWAY, P.H. A comparison of the abrasive wear behaviour of iron-chromium based hardfaced coatings deposited by SMAW and electric arc spraying. Wear, v.264, n.7-8, p.542-549, 2008.

[17] WIBAO, W.; HUA, L. Metal powder thermal behaviour during the plasma transferred-arc surfacing process. Surface and Coatings Technology, v.106, n.2-3, p. 156-161, 1998.

[18] MONTGOMERY, D.C. Introduction to statistical quality control. 4.ed. New York: Jonhn Wiley \& Sons, 2004.

[19] BRANAGAN, D.J.; MARSHALL, M.C.; MEACHAM, B.E. High toughness high hardness iron based PTAW weld materials. Materials Science and Engineering, v. A428, n.1-2, p.116-123, 2006.

[20] GATTO, A.; BASSOLI, E.; FORNARI, M. Plasma transferred arc deposition of powdered high performances alloys: process parameters optimization as a function of alloy and geometrical configuration. Surface \& Coatings Technology, v.187, p.265-271, 2004.

[21] AOH, J.N.; CHEN, J.C. On the wear characteristics of cobalt-based hardfacing layer after thermal fatigue and oxidation. Wear, v.250, n. 1-12, p.611-620, 2001.

[22] KIM, H.-J.; YOON, B.H.; LEE, C.H. Wear performance of the Fe-based alloy coatings produced by plasma transferred arc weld-surfacing process. Wear, v.249, n.10-11, p.846-852, 2001. [23] BOURITHIS, E.; TAZEDAKIS, A.; PAPADIMITRIOU, G. A study on the surface treatment of "Calmax" tool steel by a plasma transferred arc (PTA) process. Journal of Materials Processing Technology, v.128, n.1-3, p.169-177, 2002.

[24] REIS, R.P.; SCOTTI, A. Fundamentos e prática da soldagem a plasma. Sào Paulo: Artliber Editora Ltda, 2007.

[25] OLIVEIRA, M.A. Estudo da soldagem plasma com alimentação automática de arame para aplicação em revestimentos metálicos. 2001. Dissertação (Mestrado em Engenharia Mecânica) - Programa de Pós-Graduação em Engenharia Mecânica, UFSC, Florianópolis.

[26] MARCONI, M. MARCONI, B. Tecnologie del Plasma PTA. On line: CD-ROM, v. 11, 2002.

[27] YAEDU, A.E., D`OLIVEIRA, A.S.C.M. Cobalt based alloy PTA hardfacing on different substrate steels. Materials Science and Technology, v. 21, n.4, 2005. 